\title{
Insulin increases cyclic nucleotide content in human vascular smooth muscle cells: a mechanism potentially involved in insulin- induced modulation of vascular tone
}

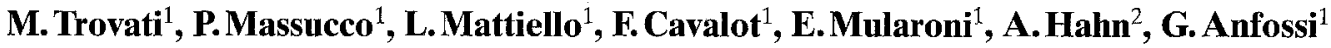 \\ ${ }^{1}$ Diabetes Unit, Department of Clinical and Biological Sciences of the University of Turin, San Luigi Gonzaga Hospital, \\ Orbassano (Turin), Italy \\ ${ }^{2}$ Research Department, Basel University, Basel, Switzerland
}

\begin{abstract}
Summary It has been suggested that insulin exerts a vasodilating effect, but the mechanisms involved are not completely understood. Since cyclic nucleotides mediate the vasodilation induced by endogenous substances, such as prostacyclin and nitric oxide, we aimed to investigate the influence of insulin (concentration range $240-960 \mathrm{pmol} / \mathrm{l}$ ) on both cyclic adenosine monophosphate (cAMP) and cyclic guanosine monophosphate (cGMP) content in human vascular smooth muscle cells. Insulin dose-dependently increased both nucleotides (cAMP: from $0.7 \pm 0.1$ to $2.6 \pm 0.4 \mathrm{pmol} / 10^{6}$ cells, $p=0.0001$; cGMP: from $1.3 \pm 0.2$ to $3.4 \pm 0.7 \mathrm{pmol} / 10^{6}$ cells, $p=0.033$ ). This increase is receptor-mediated, since it was blunted when cells were preincubated with the tyrosine kinase inhibitor genistein. The effect of insulin remained significant $(p=0.0001)$ when preincubation with the phosphodiesterase inhibitor theophylline prevented cyclic nucleotide catabolism. The increase of cGMP was blunted when the cells were
\end{abstract}

preincubated with the guanylate cyclase inhibitor methylene blue, and with the nitric oxide-synthase inhibitor $\mathrm{N}^{\mathrm{G}}$-monomethyl-L-arginine. At all the concentrations tested, insulin potentiated the increase of cAMP induced by the stable prostacyclin analogue Iloprost $(p=0.0001)$, whereas only at $1920 \mathrm{pmol} / 1$ did it potentiate the cGMP increase induced by glyceryltrinitrate $(p=0.05)$. This study demonstrates that the vasodilating effects exerted by insulin may at least in part be attributable to an increase of both cGMP and cAMP via a receptor-mediated activation of adenylate and guanylate cyclases in human vascular smooth muscle cells and that the insulin effect on cGMP is mediated by nitric oxide. [Diabetologia (1995) 38: 936-941]

Key words Insulin, arterial hypertension, vasodilation, vascular smooth muscle cells, cyclic adenosine monophosphate, cyclic guanosine monophosphate, nitric oxide.
Received: 7 October 1994 and in revised form: 4 January 1995

Corresponding author: Prof. M. Trovati, Diabetes Unit, Department of Clinical and Biological Sciences of the University of Turin, San Luigi Gonzaga Hospital, I-10043 Orbassano (Torino), Italy

Abbreviations: cAMP, cyclic adenosine monophosphate; cGMP, cyclic guanosine monophosphate; PDE, phosphodiesterases; NO, nitric oxide; hVSMC, human vascular smooth muscle cells; L-NMMA, $\mathrm{N}^{\mathrm{G}}$-monomethyl-L-arginine; GTN, glyceryltrinitrate; BSA, bovine serum albumin; NIDDM, noninsulin-dependent diabetes mellitus; MEM, minimal essential medium; RIA, radioimmunoassay.
Insulin-resistant states, such as obesity, impaired glucose tolerance and non-insulin-dependent diabetes mellitus (NIDDM), are characterised by elevated insulin concentrations and show a high prevalence of arterial hypertension [1], suggesting that insulin could play an important role in the pathogenesis of hypertension.

This suggestion is supported by observations that insulin induces sodium reabsorption [2], stimulates catecholamine release and activates the sympathetic nervous system [3-5], increases renin and angiotensin II production [6], enhances plasma endothelin-1 concentrations [7] and its release from both vascular endothelial [8] and smooth muscle cells [9] and activates the sodium hydrogen antiporter system [10]. 
Surprisingly, however, systemic insulin infusion in euglycaemic conditions does not acutely increase blood pressure, but rather increases blood flow [1113]. Although the latter effect has not been confirmed with insulin infused in the local forearm circulation $[5,14]$, it has been unequivocally shown that insulin does not have vasoconstricting properties per se. In experimental animals, it has been shown, using vascular ring segments, that insulin reduces the response to vasoconstrictors and increases the response to vasodilators $[15,16]$. Therefore, it has been proposed that insulin exerts a vasodilating effect [17], that is normally counterbalanced by the different actions described above (sodium reabsorption, sympathetic nervous system activation, angiotensin II and endothelin1 release, etc.), so that in normal subjects blood pressure values remain unchanged. Only in patients with autonomic neuropathy, who lack the adrenergic response, does insulin administration cause a decrease in blood pressure [18]. Since in insulin-resistant states, such as NIDDM, the vasodilating effect of insulin is attenuated [12], it could be supposed that a vascular resistance to the effects of insulin could play a role in the pathogenesis of arterial hypertension.

The mechanism by which insulin exerts its putative direct vasodilating effect has not been completely clarified. Some investigators have shown that insulin attenuates the increases in calcium fluxes elicited by vasoconstricting agents, such as angiotensin II and arginine vasopressin, in rat vascular smooth muscle cells $[19,20]$.

In the present study, we planned to investigate the effects of insulin on cyclic adenosine monophosphate (cAMP) and cyclic guanosine monophosphate (cGMP) content in human vascular smooth muscle cells (hVSMC): these nucleotides account for the vasodilating and platelet anti-aggregating effects exerted by some physiological agents, such as prostacyclin for cAMP [21] and nitric oxide (NO) for cGMP [22]. Various effects of insulin on cyclic nucleotides have already been reported in other cell types. As far as cAMP is concerned, insulin stimulates its catabolism enhancing some phosphodiesterase activities [23-25]: as a consequence, in adipose tissue insulin decreases cAMP content and this effect accounts for its antilipolytic action [26]; on the other hand, insulin, at physiological concentrations, increases the responses of human platelets to substances enhancing cAMP values, such as prostacyclin [27]. As far as cGMP is concerned, insulin increases its concentrations in adipocytes and hepatocytes [28], and activates soluble guanylate cyclase in the liver [29]; furthermore, we recently demonstrated that the insulininduced reduction of platelet aggregation [30] is attributable to the insulin-induced increase of platelet cGMP concentrations [31]. This study investigates the effects of insulin on cAMP and cGMP in hVSMC. In particular, we aimed to establish: a) whether insulin affects cAMP and cGMP content in hVSMC by a dose-dependent mechanism;

b) whether this putative insulin effect is modified by inhibition of catabolic enzymes phosphodiesterases (PDE);

c) whether this putative insulin effect is modified by inhibition of synthetic enzymes;

d) whether this putative insulin effect is modified by inhibition of tyrosine kinase, an enzyme coupled with the insulin receptor;

e) whether insulin modifies the cAMP and cGMP production induced by the vasodilating agents prostacyclin and nitrates;

f) whether the putative insulin effect on cGMP is due to an insulin-induced stimulation of NO formation.

\section{Materials and methods}

Chemicals. Human recombinant insulin was obtained from Calbiochem (La Jolla, Calif., USA); genistein, theophylline, forskolin and methylene blue were from Sigma Chemical Co. (St.Louis, Mo., USA); $\mathrm{N}^{\mathrm{G}}$-monomethyl-L-arginine (LNMMA) was obtained from Bachem (Bubendorf, Switzerland); glyceryltrinitrate (GTN) was obtained from Simes S. p. A. (Milan, Italy); Iloprost, a stable prostacyclin analogue, was a gift from Schering S. p. A. (Milan, Italy). Human insulin was dissolved in modified Tyrode's buffer [32] containing bovine serum albumin (BSA) ((in mmol/l) $144 \mathrm{NaCl}, 2.7 \mathrm{KCl}$, $11.9 \mathrm{NaHCO}_{3}, 0.4 \mathrm{NaH}_{2} \mathrm{PO}_{4}$ and 0.04 bovine serum albumin, $\mathrm{pH}$ 7.4). L-NMMA, methylene blue and theophylline were dissolved in modified Tyrode's buffer without BSA. Genistein was dissolved in dimethylsulfoxide, in final concentrations that did not exceed $0.25 \%$ (35 mmol/1).

Cell cultures. Experiments were performed on hVSMC derived from microarterioles obtained from patients undergoing abdominal surgery. The isolation and characterization procedures have been extensively described elsewhere [33]. Briefly, the cells were phenotypically characterised and checked for the presence of smooth muscle cell $\alpha$-actin and the absence of factor VIII staining with a fluorescein isothiocyanate-conjugated antibody specific for Factor VIII antigen, to exclude the presence of endothelial cells in the cell preparation. Cells were cultured using minimal essential medium (MEM) [32] supplemented with $10 \%$ fetal calf serum, $10 \mathrm{mmol} / 1$ glutamine, and antibiotics, and buffered with $10 \mathrm{mmol} / \mathrm{l} \mathrm{N}$-tris (hydroxymethyl) methyl-2-aminoethane-sulfonic acid (TES) and $10 \mathrm{mmol} /$ $1 \mathrm{~N}$-(2-hydroxyethyl) piperazine- $\mathrm{N}^{1}$-(2-ethanesulfonic acid) (HEPES). For the experiments, cells were used between passages 5 and 8 and were cultured in 6-well plates until $70 \%$ confluence was achieved; then the medium with serum was removed and cells were made quiescent by serum starvation and culture in MEM containing $0.1 \%$ BSA, glutamine, buffers and antibiotics (MEM/BSA). After 48-h quiescence, the medium was removed and, following three washes with Hank's solution, $2 \mathrm{ml}$ fresh MEM/BSA was added to the cell layer.

Cyclic nucleotide determination. Cyclic nucleotide levels were measured after the incubation of hVSMC with different substances, as described below. At the end of each incubation period, the medium was removed from each well and $300 \mu l$ of absolute ethanol was added to permeabilize the cells. A complete evaporation of ethanol was obtained under shaking. 
938
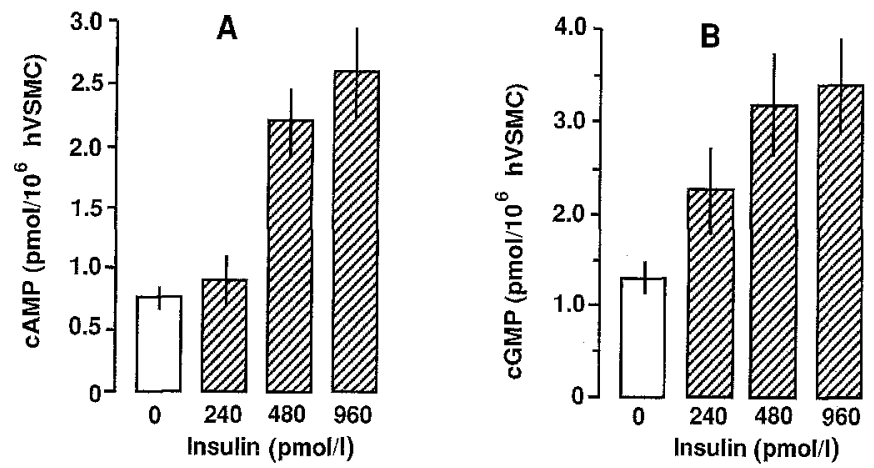

Fig. 1. A. Influence of $120-\mathrm{min}$ hVSMC incubation with increasing insulin concentrations on the hVSMC content of cAMP ( $n=6$ experiments, $p=0.0001)$. cAMP values in samples incubated with insulin at concentrations $\geq 480 \mathrm{pmol} / \mathrm{l}$ were significantly higher than basal values $(p=0.001$ and $p=0.0001$ for insulin 480 and $920 \mathrm{pmol} / 1$, respectively). B. Influence of 120 -min hVSMC incubation with increasing insulin concentrations on the hVSMC content of cGMP $(n=12$ experiments, $p=0.033$ ). cGMP values in samples incubated with insulin were significantly higher than basal values ( $p=0.05, p=0.013$ and $p=0.007$ for 240,480 and $920 \mathrm{pmol} / \mathrm{l}$ insulin, respectively)

Cyclic nucleotides were then dissolved in $300 \mu$ acetate buffer and kept at $-70^{\circ} \mathrm{C}$ until the assays. cAMP and cGMP were measured by radioimmunoassay (RIA) kits (Diagnostic Products Corporation, Los Angeles, Calif., USA and Advanced Magnetics Inc., Cambridge, Mass., USA, respectively). As far as cAMP is concerned, the sensitivity of the assay is less than $0.01 \mathrm{pmol} / 0.1 \mathrm{ml}$, the cross-reactivity with the nucleotides is $100 \%$ for cAMP, less than $1 \%$ for cGMP, less than $0.001 \%$ for AMP, GDP, ATP, GTP, intra-assay coefficient of variation $4.8 \%$. For the cGMP assay (acetylated method) the sensitivity is less than $0.3 \mathrm{fmol} / 0.1 \mathrm{ml}$, the specificity is $100 \%$ for cGMP, less than $0.6 \%$ for cAMP, less than $0.001 \%$ for GMP, GDP, ATP and GTP, intra-assay coefficient of variation $5.3 \%$.

\section{Study design}

a) To determine dose-dependent effects of insulin on cyclic nucleotides, hVSMC were incubated at $37^{\circ} \mathrm{C}$, for $120 \mathrm{~min}$, in the presence of $0,240,480$, and $960 \mathrm{pmol} / 1$ human recombinant insulin: these concentrations commonly occur in the postprandial period both in healthy $(240-480 \mathrm{pmol} / 1)$ and in insulin-resistant subjects (240-960 pmol/l) and are commonly measured during the oral glucose tolerance test [9].

b) To determine whether the influence of insulin on cyclic nucleotide levels involves PDE, hVSMC were preincubated for $20 \mathrm{~min}$ with the unselective PDE inhibitor theophylline $(500 \mu \mathrm{mol} / \mathrm{l})$ before addition of insulin.

c) To investigate whether insulin elevates cGMP levels via guanylate cyclase activation, hVSMC were preincubated for 20 min with the guanylate cyclase inhibitor methylene blue $(50 \mu \mathrm{mol} / 1)$ before addition of insulin.

d) To clarify the involvement of receptor tyrosine kinase activity on the effects of insulin on cyclic nucleotides, hVSMC were preincubated for $20 \mathrm{~min}$ with the tyrosine kinase inhibitor genistein $(10 \mathrm{nmol} / \mathrm{l})$ before addition of insulin.
M. Trovati et al.: Insulin increases cyclic nucleotides in hVSMC

e) To verify whether the influence of insulin on hVSMC cyclic nucleotides potentiates the effects of substances able to activate adenylate or guanylate cyclases, hVSMC were incubated for $120 \mathrm{~min}$ with insulin and then incubated for a further $5 \mathrm{~min}$ with the stable prostacyclin analogue Iloprost $(500 \mathrm{pg} /$ $\mathrm{ml})$, or forskolin $(2 \mu \mathrm{mol} / \mathrm{l})$ or $\mathrm{GTN}(100 \mu \mathrm{mol} / \mathrm{l})$. These experiments have been additionally performed following a 20-min preincubation of $\mathrm{hVSMC}$ with theophylline $(500 \mu \mathrm{mol} / \mathrm{l})$. In the experiments with GTN, we also incubated the cells at a supraphysiological insulin concentration of $1920 \mathrm{pmol} / \mathrm{l}$.

f) To verify whether insulin affects platelet cGMP concentrations through an effect on the hVSMC synthesis of NO, the effects of insulin on cGMP were measured after 20 -min preincubation with the NO-synthase inhibitor L-NMMA ( $1 \mathrm{mmol} / \mathrm{l}$ ).

\section{Statistical analysis}

Data are expressed as mean \pm SEM. For every experimental series, 6-12 experiments were performed. Statistical analysis was carried out by means of analysis of variance (ANOVA) to determine the statistical significance of the dose-response effects and by the unpaired Student's $t$-test when only two values had to be compared.

\section{Results}

a) Insulin induced a dose-dependent increase of both intracellular cAMP ( $p=0.0001$, Fig. 1 A) and cGMP $(p=0.033$, Fig. 1B) in hVSMC. Cyclic nucleotide values are significantly elevated above baseline levels for insulin concentrations of $480 \mathrm{pmol} / 1$ or above for cAMP $(p=0.001$ and $p=0.0001$ for 480 and $960 \mathrm{pmol} / \mathrm{l}$ insulin, respectively), and for insulin concentrations of $240 \mathrm{pmol} / 1$ or above for cGMP ( $p=$ $0.05, p=0.013$ and $p=0.007$ for 240,480 and $960 \mathrm{pmol} / \mathrm{l}$ insulin, respectively).

b) As shown in Figure $2 \mathrm{~A}$ and 2B, the PDE inhibitor theophylline significantly increased the concentrations of both nucleotides $(p=0.0001)$; in the presence of theophylline, the insulin-induced increases in cAMP and cGMP remained significant (ANOVA, $p=0.0001$ ), and the effect of insulin was already evident at the concentration of $240 \mathrm{pmol} / \mathrm{l} ; p=0.002$ for cAMP and $p=0.007$ for cGMP.

c) Following the preincubation of hVSMC with the guanylate cyclase inhibitor methylene blue, the insulin-induced increase of cGMP was blunted. In the presence of $50 \mu \mathrm{mol} / 1$ methylene blue, cGMP concentrations (pmol $/ 10^{6}$ cells) were $1.2 \pm 0.05$ without insulin, $1.2 \pm 0.08$ and $1.0 \pm 0.06$ with 480 and $960 \mathrm{pmol} / 1$ insulin, respectively.

d) The insulin-induced increase of cyclic nucleotides in hVSMC was completely abolished in the presence of the tyrosine kinase inhibitor genistein. In the samples with $960 \mathrm{pmol} / 1$ insulin, cAMP values $\left(\mathrm{pmol} / 10^{6}\right.$ 

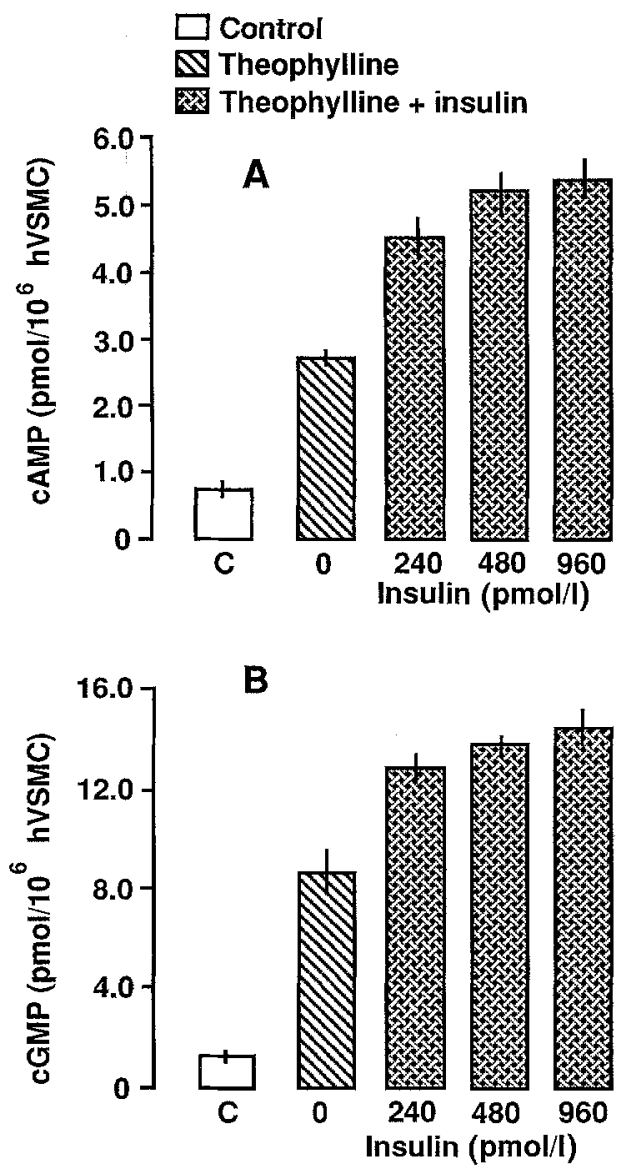

Fig. 2. A. Influence of 120 -min hVSMC incubation with increasing insulin concentrations, after 20 -min preincubation with $500 \mu \mathrm{mol} / \mathrm{l}$ of the phosphodiesterase inhibitor theophylline, on the hVSMC content of cAMP ( $n=6$ experiments, $p=0.0001$ ). Theophylline induced a significant increase in basal cAMP values $(p=0.0001)$. cAMP values in samples with insulin incubation were significantly higher than values in samples with theophylline alone $(p=0.002$ for $240 \mathrm{pmol} / 1$ insulin, $p=0.0001$ for 480 and $920 \mathrm{pmol} / /$ insulin). B. Influence of 120 min $\mathrm{hVSMC}$ incubation with increasing insulin concentrations, after 20 -min preincubation with $500 \mu \mathrm{mol} / 1$ of the phosphodiesterase inhibitor theophylline, on the hVSMC content of cGMP ( $n=6$ experiments, $p=0.0001$ ). Theophylline induced a significant increase of basal cGMP values $(p=0.0001)$. cGMP values in samples with insulin incubation at concentrations of 240,480 and $920 \mathrm{pmol} / \mathrm{l}$ were significantly higher than values in samples with theophylline alone $(p=0.007$ for $240 \mathrm{pmol} / \mathrm{l}$ insulin, $p=0.003$ for 480 and $920 \mathrm{pmol} / \mathrm{l}$ insulin)

cells) were $2.6 \pm 0.4$ ( $p=0.0001$ vs baseline) in the absence and $0.7 \pm 0.1$ (NS vs baseline) in the presence of genistein, cGMP values were $3.4 \pm 0.7$ ( $p=0.007$ vs baseline) in the absence and $1.2 \pm 0.04$ (NS vs baseline) in the presence of genistein.

e) The stimulation of adenylate cyclase activity in hVSMC by Iloprost caused a significant increase of basal cAMP values $(p=0.002)$. Addition of insulin further elevated cAMP concentrations: for instance, in cells exposed to $240 \mathrm{pmol} / 1$ insulin and to Iloprost, cAMP values ( $\mathrm{pmol} / 10^{6}$ cells) were significantly high-
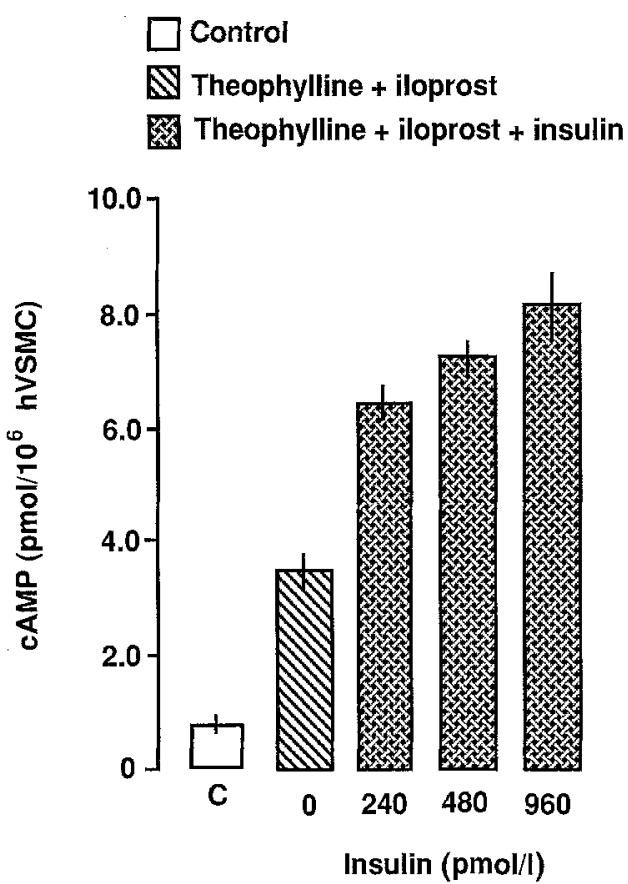

Fig.3. Influence of 120-min hVSMC incubation with increasing insulin concentrations, in the presence of 5-min incubation with $500 \mathrm{pg} / \mathrm{ml}$ of the stable prostacylin analogue Iloprost and a 20 -min preincubation with $500 \mu \mathrm{mol} / 1$ of the phosphodiesterase inhibitor theophylline, on the hVSMC content of cAMP ( $n=10$ experiments, $p=0.0001$ ). The incubation with Iloprost plus theophylline induced a significant increase of basal cAMP values ( $p=0.0001)$. cAMP values in samples with insulin incubation at concentrations of 240,480 and $920 \mathrm{pmol} / 1$ were significantly higher than values in samples with theophylline plus Iloprost alone $(p=0.0001)$

er than in cells exposed to Iloprost alone $(1.5 \pm 0.2 \mathrm{vs}$ $1.0 \pm 0.06 \mathrm{pmol} / 10^{6}$ cells, $p=0.05$ ). A potentiation of the effect of Iloprost on hVSMC cAMP content by insulin was also observed in the presence of theophylline: this phenomenon was highly significant from the insulin concentration of $240 \mathrm{pmol} / 1 \quad(p=0.0001)$ (Fig. 3).

The effect of forskolin on cAMP value was also enhanced by insulin, cAMP values in the presence of forskolin $+240 \mathrm{pmol} / 1$ insulin being significantly higher than values with forskolin alone $(1.7 \pm 0.1$ vs $1.3 \pm 0.1 \mathrm{pmol} / 10^{6}$ cells, $\left.p=0.018\right)$.

The stimulation of guanylate cyclase activity by GTN caused a significant increase of cGMP values $(p=0.008)$. Insulin potentiated the GTN-induced enhancement of cGMP only at the $1920 \mathrm{pmol} / \mathrm{l}$ concentration, both in the absence $(2.2 \pm 0.18$ vs $2.8 \pm$ $0.22 \mathrm{pmol} / 10^{6}$ cells, $\left.p=0.05\right)$ and in the presence $\left(18.2 \pm 1.3\right.$ vs $23.5 \pm 1.2 \mathrm{pmol} / 10^{6}$ cells, $\left.p=0.012\right)$ of PDE inhibition by theophylline.

f) In hVSMC incubated with insulin and L-NMMA, cGMP values at all the insulin concentrations tested (0-960 pmol/l) were significantly lower than cGMP values in hVSMC incubated with insulin alone 
940

$(\mathrm{p}=0.0001)$. L-NMMA reduced by $35.6 \%$ basal cGMP values and by $84.6 \%$ the cGMP increase induced by $960 \mathrm{pmol} / \mathrm{l}$ insulin.

\section{Discussion}

This study demonstrates that insulin induces, at physiological concentrations, a dose-dependent increase of hVSMC content of both cAMP and cGMP, wellknown intracellular mediators of vasodilation. These results are in agreement with a recent study carried out with platelets, in which we demonstrated that insulin causes a dose-dependent increase of cGMP, accounting for the anti-aggregating effect of the hormone [31].

In order to clarify the mechanisms involved in the insulin-induced changes of cyclic nucleotides in hVSMC, we investigated the action of insulin on their synthesis and catabolism.

The experiments carried out with theophylline clearly indicate that inhibition of catabolism does not impair the insulin-induced increase of cyclic nucleotides, suggesting an insulin-mediated increase of their synthesis. Obviously, since theophylline prevents both cAMP and cGMP breakdown, adenylate and guanylate cyclase activity is amplified, with a consequent increase in cyclic nucleotide concentrations.

The inability of insulin to elevate cGMP in the presence of the guanylate cyclase inhibitor methylene blue shows that insulin stimulates this enzyme activity in hVSMC. It is known that VSMC have a NOsynthase activity $[34,35]$. The selective $\mathrm{NO}$-synthase inhibitor L-NMMA strongly inhibited the insulin-induced increase of cGMP. This fact demonstrates for the first time that insulin activates the NO-synthase in hVSMC, inducing the production of NO that increases cGMP by stimulating guanylate cyclase.

As far as cAMP is concerned, our results invite speculation, even if we did not perform direct enzyme measurements: actually, since at the concentration of $240 \mathrm{pmol} / 1$ the insulin-induced increase of cAMP is greater in the presence (about $65 \%$ ) than in the absence of PDE inhibition by theophylline (about $20 \%$ ), it can be assumed that also in hVSMC - as in other cell types [23-25] - insulin stimulates cAMP catabolism and that this action of insulin is overcome at higher insulin concentrations by the prevailing effects on cAMP synthesis. A different balance between the insulin influence on cAMP synthesis and catabolism could account for the fact that in different cells insulin exerts different effects on cAMP content: for instance, the insulin-induced decrease of cAMP in adipose tissue [26].

The lack of any insulin-induced increase of cyclic nucleotides when hVSMC are exposed to genistein, a tyrosine kinase inhibitor, demonstrates that this ef-
M. Trovati et al.: Insulin increases cyclic nucleotides in hVSMC

fect is mediated via receptor tyrosine kinase activation, as we recently described for the insulin-induced cGMP increase in platelets [31]. Since tyrosine kinase is mainly coupled to receptors for growth factors [36], among them insulin-like growth factor-1, our study was not able to exclude a possible effect of insulin also through insulin-like growth factor-1 receptors.

Concerning the ability of insulin to influence the action of well-known vasodilating agents in hVSMC, we demonstrated that, at all the concentrations tested, insulin increases the effects of the stable prostacyclin analogue Iloprost on cAMP content. This insulin effect is amplified when PDE are inhibited by theophylline, indicating that the potentiation occurs at the level of adenylate cyclase activation. It is noteworthy that in this study we used threshold concentrations of Iloprost, in order to avoid a pharmacologic effect of the agent.

The ability of insulin to enhance the cAMP increase induced by forskolin, that directly activates adenylate cyclase with a receptor-independent mechanism [37], demonstrates that the potentiating effect is not specific for prostacyclin, that acts after a specific binding to the cells, but is extended to other substances able to increase cAMP synthesis.

The insulin-induced potentiation of substances able to increase cGMP in hVSMC does not have physiological relevance, since insulin enhances the effect of GTN only at very high, non-physiological concentrations. This observation is in agreement with the fact that insulin does not increase the vasodilation induced by sodium nitroprusside in rat aortic ring segments [36].

In conclusion, the results of this study show that, in the complex, multifactorial insulin-induced modulation of vascular tone, insulin is able not only to potentiate the action of endothelium-derived substances, such as prostacyclin, but also to increase the hVSMC content of both cAMP and cGMP, wellknown mediators of vasodilation and that the insulin-induced cGMP increase in hVSMC is due to NO formation.

As already mentioned, recent studies carried out in vivo in humans claim that in insulin-resistant states the vasodilating effects of insulin are reduced [12]. We recently described the same phenomenon for the platelet anti-aggregating effect [38]. Since some actions of insulin are similar to those of vasodilating substances (i. e., the increase of cyclic nucleotide content), our results invite speculation that insulin-resistant conditions could exibit a reduced insulin-induced vasodilation because insulin resistance also occurs at the level of hVSMC. In this light, a "vascular" insulin resistance may play a role in the pathogenesis of arterial hypertension. Obviously, further studies are needed to verify whether this hypothesis is correct. 


\section{References}

1. DeFronzo RA, Ferrannini E (1991) Insulin resistance: a multifaceted syndrome responsible for NIDDM, obesity, hypertension, dyslipidemia, and atherosclerotic cardiovascular disease. Diabetes Care 14: 173-194

2. DeFronzo RA, Cooke CR, Andres R, Faloona GR, Davis PJ (1975) The effect of insulin on renal handling of sodium, potassium, calcium and phosphate in man. J Clin Invest 55 : 845-855

3. Rowe JW, Young JB, Minaker KL, Stevens AL, Pallotta J, Landsberg L (1981) Effect of insulin and glucose infusions on sympathetic nervous system activity in normal man. Diabetes 30: 219-225

4. Berne C, Fagius J, Pollare T, Hjemdahl P (1992) The sympathetic response to euglycaemic hyperinsulinaemia: evidence from microelectrode nerve recordings in healthy subjects. Diabetologia 35: 873-879

5. Lembo G, Napoli R, Capaldo B et al. (1992) Abnormal sympathetic overactivity evoked by insulin in the skeletal muscle of patients with essential hypertension. J Clin Invest 90:24-29

6. Trovati M, Massucco P, Anfossi G et al. (1989) Insulin influences the renin-angiotensin-aldosterone system in humans. Metabolism 38: 501-503

7. Wolpert HA, Steen SN, Istfan NW, Simonson DC (1993) Insulin modulates circulating endothelin-1 levels in humans. Metabolism 42: 1027-1030

8. Hattori Y, Kasai K, Nakamura T, Emoto T, Shimoda SI (1991) Effect of glucose and insulin on immunoreactive endothelin-1 release from cultured porcine aortic endothelial cells. Metabolism 40: 165-169

9. Anfossi G, Cavalot F, Massucco P et al. (1993) Insulin influences immunoreactive endothelin release by human vascular smooth muscle cells. Metabolism 42: 1081-1083

10. Moore RD (1981) Stimulation of $\mathrm{Na}: \mathrm{H}$ exchange by insulin. Biophys J 33: 203-210

11. Anderson EA, Balon TW, Hoffman RP, Sinkey CA, Mark AL (1991) Hyperinsulinemia produces both sympathetic neural activation and vasodilation in normal humans. $\mathbf{J}$ Clin Invest 87: 2246-2252

12. Laakso M, Edelman SV, Brechtel G, Baron AD (1992) Impaired insulin-mediated skeletal muscle blood flow in patients with NIDDM. Diabetes 41: 1076-1083

13. Vollenweider P, Tappy L, Randin D et al. (1993) Differential effects of hyperinsulinemia and carbohydrate metabolism on sympathetic nerve activity and muscle blood flow in humans. J Clin Invest 92: 147-154

14. Natali A, Buzzigoli G, Taddei S et al. (1990) Effects of insulin on hemodynamics and metabolism in human forearm. Diabetes 39: 490-500

15. Wambach GK, Liu D (1992) Insulin attenuates vasoconstriction by noradrenaline, serotonin and potassium chloride in rat mesenteric arterioles. Clin Exp Hypertens A 14: 733-740

16. Gros R, Borkowski KR, Feldman RD (1994) Human insulin-mediated enhancement of vascular $\beta$-adrenergic responsiveness. Hypertension 23: 551-555

17. Anderson EA, Mark AL (1993) The vasodilator action of insulin. Implications for the insulin hypothesis on hypertension. Hypertension 21: 136-141

18. Porcellati F, Fanelli C, Bottini P et al. (1993) Mechanisms of arterial hypotension after therapeutic dose of subcutaneous insulin in diabetic autonomic neuropathy. Diabetes 42: 1055-1064

19. Saito F, Hori MT, Fittingoff M, Hino T, Tuck ML (1993) Insulin attenuates agonist-mediated calcium mobilization in cultured rat vascular smooth muscle cells. J Clin Invest 92 : $1161-1167$ 